\title{
Effects of Rosemary and Green Tea Antioxidants on Ground Beef Patties in Traditional and Modified Atmosphere Packaging
}

\author{
Laura Yoder, Deborah L. VanOverbeke, Ranjith Ramanathan, and Gretchen G. Mafi* \\ Department of Animal and Food Sciences, Oklahoma State University, Stillwater, OK 74078, USA \\ *Corresponding author. Email: gretchen.mafi@okstate.edu (Gretchen G. Mafi)
}

\begin{abstract}
The objective of this study was to analyze the effects of rosemary (RSM) and green tea (GT) added to ground beef to extend shelf life. Four antioxidant treatments were used: control, 2,500 ppm RSM, 300 ppm GT, and 2,500 ppm RSM + 300 ppm GT (RSM + GT). Patties from each treatment $(n=42)$ were randomly packaged into one of 3 types: polyvinyl chloride (PVC) overwrap, modified atmospheric packaging (MAP), or master packages (MP). Packages of MAP and MP were flushed with $0.4 \% \mathrm{CO}, 69.6 \%$ nitrogen $\left(\mathrm{N}_{2}\right)$, and $30 \%$ carbon dioxide $\left(\mathrm{CO}_{2}\right)$. Patties in PVC and MAP were placed directly into display cases for $7 \mathrm{~d}$, and MP patties were placed in dark storage for $7 \mathrm{~d}$ and then in display cases for another $7 \mathrm{~d}$. Instrumental and subjective color, lipid oxidation, and sensory panel scores were measured. In MAP, patties with GT had increased $(P<0.05) a^{*}$ and chroma values by day 6 of retail display. In MP at $3 \mathrm{~d}$ of retail display, GT patties exhibited increased $(P<0.05) L^{*}$ values (lighter), display color (deeper red), and surface discoloration (greater discoloration) scores compared with RSM + GT patties. However, GT and RSM patties were not different $(P>0.05)$ for these parameters. Trained sensory panelists did not detect a difference between control and GT patties for the green-hay attribute; however, RSM patties had highly detectable $(P<0.05)$ green-hay flavor. Panelists were unable to detect any differences $(P>0.05)$ for rancid or fatty flavors regardless of treatment. Patties in MAP were more color stable than those in PVC after $6 \mathrm{~d}$ of retail display. In conclusion, patties in MP with GT showed positive instrumental and objective color measurements, as well as lipid oxidation values after $3 \mathrm{~d}$ of display, combined with undetectable flavor, warranting further research.
\end{abstract}

Key words: ground beef, packaging, shelf life, meat color

Meat and Muscle Biology 5(1): 25, 1-12 (2021) doi:10.22175/mmb.11697

Submitted 2 November $2020 \quad$ Accepted 8 April 2021

\section{Introduction}

Consumers believe color to be one of the most important fresh meat characteristics when purchasing meat, and unacceptable color leads consumers to believe that the product may be spoiled (Font-i-Furnols and Guerrero, 2014). Additionally, consumers prefer fresh beef to be a bright red color and believe that any other color is unacceptable (Bechtel et al., 1986). A recent report from a market research group indicated that, in 2019, the United States lost \$3 billion alone, and $\$ 14.2$ billion was lost globally, because of meat discoloration (Maia Research Analysis,
2020). Metmyoglobin is the pigment responsible for browning and discoloration of meat products at almost every step of the meat processing chain and is a primary factor that can off-put consumers at the retail case (Ramanathan et al., 2019). Oxidation of compounds in meat, including myoglobin, can promote deterioration of color, promote off-flavors, and shorten shelf life (Falowo et al., 2014).

Antioxidants can be found in many plants, and their ability to reduce oxidation is actually more effective than synthetic antioxidants (Oswell et al., 2018). According to the Code of Federal Regulations, ingredients like rosemary and green tea extracts do not 
have to be labeled individually and can instead be labeled as "spices" or "flavors" (Oswell et al., 2018). Both rosemary (Lee et al., 2005; Balentine et al., 2006) and green tea (Liu et al., 2015; Jayawardana et al., 2019) have been shown to reduce lipid oxidation. Additionally, rosemary and green tea have been shown to improve color stability in meat products when packaged in polyvinyl chloride (PVC) and modified atmosphere packaging (MAP) (Sánchez-Escalante et al., 2003; Bañón et al., 2007). Packaging type can impact lipid and protein oxidation levels. Traditional PVC overwrap trays are oxygen permeable, which can result in quicker rates of oxidation. However, MAP is flushed with different gases to improve shelf stability by adding carbon monoxide $(\mathrm{CO})$ and carbon dioxide $\left(\mathrm{CO}_{2}\right)$ and lowering or eliminating $\mathrm{O}_{2}$, owing to myoglobin creating a bond with the carbon ion, which is stable for a longer period of time than a bond with $\mathrm{O}_{2}$ (McMillin, 2017). In the United States, the use of CO has been approved and considered "generally recognized as safe" since 2002 for use of up to $0.4 \%$ (Rulis, 2002). Sørheim et al. (1999) showed that use of CO up to $1 \%$ can increase shelf life and color stability of meat because $\mathrm{CO}$ has greater affinity for myoglobin than oxygen when MAP is being used. However, there are limited studies that have investigated the combination of antioxidant treatments and multiple packaging types to extend meat shelf life. Thus, the objective of this study was to evaluate the effects of rosemary and green tea in ground beef patties in traditional packaging and MAP types in an effort to achieve a longer shelf life.

\section{Materials and Methods}

\section{Raw material preparation, proximate analysis, and $\mathrm{PH}$}

Two USDA Choice chuck rolls (Institutional Meat Purchase Specifications \#116A) were selected at random from a commercial processing facility. Carcasses were chilled $72 \mathrm{~h}$ postmortem prior to being fabricated. Chuck rolls from 2 carcasses were vacuum packaged and transported to the Robert M. Kerr Food and Agricultural Products Center at Oklahoma State University, Stillwater. Chuck rolls were removed from vacuum packages, $\mathrm{pH}$ of each chuck roll was measured 3 times, and $\mathrm{pH}$ readings were averaged $(\mathrm{pH}=5.67)$. Chuck rolls were fabricated into smaller pieces for ease of grinding, then ground together with a $9 \mathrm{~mm}$ plate, and then finely ground with a $3 \mathrm{~mm}$ plate utilizing a
Biro mixer grinder (Model AFMG-24, Biro Manufacturing Company, Marblehead, $\mathrm{OH}$ ) to homogenize the sample. Six random ground chuck samples were measured using near infrared (NIR) with an AOAC (2007.04)-approved NIR spectrophotometer (FoodScan Lab Analyzer, Serial No. 91753206, Foss, NIR systems Inc., Slangerupgade, Denmark). Protein, fat, and moisture contents ranged from $20.6 \%$ to $21.4 \%, 11.8 \%$ to $13.5 \%$, and $65.4 \%$ to $66.3 \%$, respectively. Samples of the ground chuck were randomly assigned to one of 4 treatment groups: control, rosemary, green tea, and rosemary + green tea. Rosemary and green tea were added in powder form. Antioxidant levels were based on results from Schilling et al. (2018). Rosemary was added at $2,500 \mathrm{ppm}$, green tea at $300 \mathrm{ppm}$, and rosemary + green tea at $2,500 \mathrm{ppm}+300 \mathrm{ppm}$. Control ground chuck was hand mixed for $15 \mathrm{~s}$ with no added ingredients. Ground chuck with added ingredients was hand mixed for $15 \mathrm{~s}$. After mixing, $115 \mathrm{~g}$ patties $(n=168)$, which measured $1.39 \mathrm{~cm}$ thick and $10.795 \mathrm{~cm}$ in diameter, were formed using an Adjust-A-Burger patty press (Kitchen Art, Adjust-A-Burger Patty Press, 4.25" diameter). All ground beef not utilized for patties, proximate analysis, or initial lipid oxidation testing was vacuum packaged and frozen to be used for trained sensory panel testing.

\section{Packaging and storage}

Twelve patties per antioxidant treatment were equally and randomly assigned to $\mathrm{PVC}$ or MAP $\left(0.4 \% \mathrm{CO}, 69.6 \% \mathrm{~N}_{2}\right.$, and $\left.30 \% \mathrm{CO}_{2}\right)$ packaging treatments. Eighteen patties per antioxidant treatment were equally assigned at random to master packages (MP; PVC inside package flushed with $0.4 \% \mathrm{CO}, 69.6 \%$ $\mathrm{N}_{2}$, and $30 \% \mathrm{CO}_{2}$ ). The number of patties differed for each packaging type to ensure a consistent number $(n=6)$ for each evaluation day (days 3, 6, 9, and 12). White polystyrene trays (NoviPro; $16.5 \mathrm{~cm} \times 21.75$ $\mathrm{cm} \times 3.22 \mathrm{~cm}$ ) were obtained from NoviPax (Oak Brook, IL) and overwrapped with PVC, white MAP trays (Rock-Tenn DuraFresh rigid trays) were obtained from Cryovac Sealed Air (Duncan, SC), and MP $(68.5 \mathrm{~cm} \times 45.7 \mathrm{~cm})$ were obtained from Amcor Flexibles North America (Yuba City, CA). Patties assigned to PVC or MP were placed into PVC trays with absorbent pads and overwrapped with a PVC film $(15,500$ $16,275 \mathrm{~cm}^{3} \mathrm{O}_{2} / \mathrm{m}^{2} / 24 \mathrm{~h}$ at $23^{\circ} \mathrm{C}$; E-Z Wrap Crystal Clear Polyvinyl Chloride Wrapping Film, Koch Supplies, Kansas City, MO). Patties assigned to MP were then placed inside a MP along with a FreshPax oxygen scavenger (Multisorb Technologies, Buffalo, 
$\mathrm{NY})$, flushed with a tri-gas blend $\left(0.4 \% \mathrm{CO}, 69.6 \% \mathrm{~N}_{2}\right.$, and $30 \% \mathrm{CO}$ ) for $10 \mathrm{~s}$, and heat sealed with a double chamber packaging machine (C500, Multivac, Wolfertschweden, Germany). One package representing all 4 antioxidant treatments was represented in each MP. Patties assigned to MAP utilized a multi-layer barrier film (LID 1050 film) obtained from Cryovac Sealed Air (Duncan, SC) flushed with the same trigas blend $\left(0.4 \% \mathrm{CO}, 69.6 \% \mathrm{~N}_{2}\right.$, and $\left.30 \% \mathrm{CO}_{2}\right)$, and trays were sealed with a Mondini semi-automatic tray-sealing machine (Model CV/VG-5; G. Mondini S.P.A. Cologne, Italy). All gases were certified food grade and obtained from Stillwater Steel and Welding Supply (Stillwater, OK). The percentage of $\mathrm{O}_{2}, \mathrm{CO}_{2}$, and $\mathrm{CO}$ was verified utilizing a headspace analyzer (Bridge $900131 \quad \mathrm{O}_{2} / \mathrm{CO}_{2} / \mathrm{CO}$, Illinois Instruments, Ingleside, IL) immediately prior to placing patties in their respective packaging type.

\section{Retail display}

After packaging, MAP and PVC packages were placed in 2 coffin-style retail display cases (Model: M1-8EB; Hussmann, Bridgeton, MO) set at $4^{\circ} \mathrm{C} \pm 1^{\circ} \mathrm{C}$, under continuous LED lighting (Philips LED lamps; 12 watts, 48 inches, color temperature $=3,500^{\circ} \mathrm{K}$; Phillips, China), for $7 \mathrm{~d}$. Packages were rotated daily within each case, to minimize variance owing to temperature or light intensity caused by location in the cases. MP were kept in dark storage conditions at $4^{\circ} \mathrm{C} \pm 1^{\circ} \mathrm{C}$ for $7 \mathrm{~d}$. Temperature was monitored continuously in retail cases and dark storage to ensure that fluctuation out of range did not occur by utilizing temperature LogTag readers (LogTag TRIX-8 Temperature Data Recorder; MicroDAQ, Contoocook, NH). Prior to opening each MP, a headspace analyzer was utilized to obtain the percentage of $\mathrm{O}_{2}, \mathrm{CO}_{2}$, and $\mathrm{CO}$ after dark storage time. After opening each MP, trays were placed inside the coffin-style retail cases for $7 \mathrm{~d}$.

\section{Instrumental color, visual color panel, and lipid oxidation}

After packaging in PVC or MAP, instrumental color was measured on the surface of all patties using a HunterLab MiniScan XE Plus spectrophotometer (Model 45/0 LAV, 2.5-cm diameter aperture, illuminant A, $10^{\circ}$ observer; HunterLab, Reston, VA). Measurements were recorded at 2 different locations on each surface and utilized CIE $L^{*}, a^{*}, b^{*}$, and chroma values. Patties packaged with MAP were inverted for instrumental color measurements. Instrumental color was measured every $24 \mathrm{~h}$ on days $0-6$. Initial instrumental color measurements were collected on patties in MP on day 0 prior to patties being placed in dark storage; however, instrumental color was not measured during the dark storage period. After $7 \mathrm{~d}$ of dark storage, patties were removed from MP, and instrumental color was measured at 2 different locations, then placed in retail cases for $7 \mathrm{~d}$. Instrumental color measurements were taken every $24 \mathrm{~h}$ on days 6-12 for every patty in retail display.

A trained panel $(n=6)$ evaluated visual color every $24 \mathrm{~h}$. Each panelist was tested with the Farnsworth Munsell 100-hue test and successfully passed with a score of 50 or less. Prior to serving on the panel, panelists were trained according to American Meat Science Association (2012) guidelines. Panelists evaluated each patty every $24 \mathrm{~h}$ of display and scored the display color on an 8-point scale ( $1=$ very light red, $2=$ moderately light red, $3=$ light red, $4=$ slightly bright red, $5=$ bright red, $6=$ slightly dark red, $7=$ moderately dark red, and $8=$ dark red) and surface discoloration on a 7 -point scale $(1=$ no discoloration $0 \%$ [metmyoglobin]; $2=$ minimal discoloration $1 \%-10 \% ; 3=$ slight discoloration $11 \%-20 \% ; 4=$ small discoloration $21 \%-40 \% ; 5=$ modest discoloration $41 \%-60 \% ; 6=$ moderate discoloration $61 \%-80 \%$; and $7=$ extensive discoloration $81 \%-100 \%$ ). No guidelines were available for ground meat in MAP packaging, so the same scale was used on all patties, regardless of packaging type. Patties were randomly assigned for removal for lipid oxidation tests. These patties had instrumental and visual color measurements taken prior to removal for testing.

Lipid oxidation was measured on day 0 , from a composite sample of the raw ground chuck representing initial lipid oxidation of the raw material. On days $3,6,9$, and 12 , six patties from each antioxidant treatment $\times$ packaging type that were represented in simulated retail display were randomly selected and removed for lipid oxidation tests. Three grams of each patty was blended with $20 \%$ tricarboxylic acid solution for $10 \mathrm{~s}$ using a Waring commercial blender (Model 33BL7; New Hartford, CT) and filtered through Whatman 42 filter paper into $125 \mathrm{~mL}$ Erlenmeyer flasks. One milliliter of filtrate was combined with $1 \mathrm{~mL}$ of thiobarbituric acid solution into test tube and placed into $100^{\circ} \mathrm{C}$ water bath for $10 \mathrm{~min}$. Samples were removed from the water bath and cooled at room temperature for $5 \mathrm{~min}$. Absorbance of samples was measured at $532 \mathrm{~nm}$ using a Shimadzu UV-2600 PC spectrophotometer. Lipid oxidation results were reported as milligrams of malonaldehyde per kilogram of meat (Section XI, American Meat Science Association, 2012). 


\section{Trained sensory panel}

Sensory panels ( $n=3$ sessions) to evaluate flavor were conducted on samples from all antioxidant treatment groups. Panelists were trained in 8 training sessions to evaluate green-hay flavor, rancid flavor, and fatty flavor prior to serving on the panel utilizing modified flavor standards of the American Meat Science Association (2016). In this study, we utilized a 3-point scale for sensory panels, a modified procedure of Knobel et al. (2013) and Denzer et al. (2020), which was modified for the flavor attributes in this study. A 3-point scale was utilized to allow panelists to focus on detection of flavors since multiple levels of each antioxidant were not utilized. Panelists were trained to detect the greenhay attribute utilizing dry parsley flakes. Dry parsley flakes were provided for panelists to introduce the green-hay flavor. Once they were introduced to the flakes, they were served a 115-g piece of an 85-15 lean-to-fat ratio ground beef patty with $5 \mathrm{~g}$ of added parsley to represent a 3 on the scale (or being strongly detectable). Additionally, they were provided a sample of an 85-15 lean-to-fat ratio ground beef patty with no additives to represent a 1 on the scale (or not detectable). Finally, they were served a piece of an 85-15 lean-tofat ratio ground beef patty that was prepared with $2.5 \mathrm{~g}$ of dry parsley flakes added to represent a 2 on the scale (or slightly detectable). Panelists were trained with these anchors 3 times after being introduced to each sample to ensure ability to detect flavors. Training occurred utilizing a randomized 3-digit code to ensure no bias.

Panelists were trained to detect the fatty flavor by utilizing beef suet. A small piece of beef suet was served to panelists to introduce the fatty flavor. Once introduced to the fatty flavor, they were served a sample of a 115-g ground beef patty that was made to have a 50-50 lean-to-fat ratio with beef suet, which represented a 3 on the scale (or strongly detectable). After, panelists were provided with a sample of a ground beef patty with a 70-30 lean-to-fat ratio to represent a 2 on the scale (or slightly detectable). Finally, they were presented with a patty with a 90-10 lean-to-fat ratio to represent a 1 on the scale (or not detectable). Panelists were trained with these anchors 3 times after being introduced to each sample to ensure ability to detect flavors. Training occurred utilizing a randomized 3-digit code to ensure no bias.

Finally, panelists were trained with Wesson vegetable oil for the rancid attribute. Panelists were introduced to the rancid flavor by being provided a sample of Wesson vegetable oil that had been heated for $5 \mathrm{~min}$ and cooled. After introducing the flavor, they were served a sample of an 85-15 lean-to-fat ratio ground beef patty with $30 \mathrm{~mL}$ of Wesson vegetable oil that had been warmed for $5 \mathrm{~min}$ and cooled to room temperature. This patty would represent a 3 on the scale (or highly detectable). Additionally, panelists were served a piece of an 85-15 lean-to-fat ratio ground beef patty sample with $15 \mathrm{~mL}$ of added Wesson vegetable oil that had been heated for $5 \mathrm{~min}$ and then allowed to cool to room temperature, with this sample representing a 2 on the scale (or slightly detectable). They were also served a ground beef patty made with 85-15 lean-to-fat ratio with no added oil to represent a 1 on the scale (or not detectable). Panelists were trained with these anchors 3 times after being introduced to each sample to ensure ability to detect flavors at correct levels. Training occurred utilizing a randomized 3-digit code to ensure that blind tasting occurred. After being trained on all flavor attributes, panelists were served patties that contained 1 to 3 of the flavors at varying levels to test their ability to detect the flavor attributes correctly. Panelists were tested on their abilities to detect the mixed flavor attributes at random levels 3 times. Panelists that were able to successfully identify flavor attributes and levels participated in the sensory panel for this study.

Eight trained panelists participated in a total of 3 sessions that consisted of 8 samples per session, 2 samples per antioxidant treatment plus 2 control samples. Ground beef was thawed at $4{ }^{\circ} \mathrm{C}$ for approximately $24 \mathrm{~h}$. Ground beef (115 g) and antioxidant treatment were mixed for $15 \mathrm{~s}$ and hand formed immediately prior to cooking, following the same procedure as described earlier, and assigned a random 3-digit code. All patties were cooked on a George Foreman Grilling Machine (Model GRP99, Lake Forest, IL) to an internal temperature of $74^{\circ} \mathrm{C}$. After cooking, patties were cut according to the American Meat Science Association (2016), placed in a sample cup labeled with their corresponding code, and placed in a warmer to maintain temperature throughout the sensory evaluation time. Panelists were seated at individual booths under red lighting and were provided deionized water and salt-free crackers to cleanse their palette between samples. Two samples were served at a time, with 4 pairs served at each panel session. Panelists were asked to evaluate green-hay, rancid, and fatty flavor attributes on a 3-point scale as shown $(1=$ not detectable, $2=$ slightly detectable, and $3=$ strongly detectable).

\section{Statistical analysis}

A $2 \times 4$ factorial design was used to evaluate the main and interactive effects of PVC and MAP 
packaging types and the 4 antioxidant treatment types. For proximate analysis and $\mathrm{pH}$, means were generated using the PROC MEANS procedure of SAS version 9.4 (SAS Institute Inc., Cary, NC). Instrumental color ( $L^{*}$ and $a^{*}$ ), lipid oxidation, visual color panel, and trained sensory panel were analyzed using the MIXED procedure of SAS. Fixed variables included antioxidant treatment, display day, and packaging type. $L^{*}$ and $a^{*}$ values, milligrams of malonaldehyde per kilogram, pull day, display color and surface discoloration, and flavor scores served as the dependent variables. Panelist served as a random effect in display and sensory models. There were 48 patties in both PVC and MAP with 12 patties per treatment.

A randomized design was used to evaluate the main and interactive effects of MP packaging type and the 4 antioxidant treatment types. Instrumental color ( $L^{*}$ and $\left.a^{*}\right)$, lipid oxidation, visual color panel, and trained sensory panel were analyzed using the MIXED procedure of SAS. Fixed variables included antioxidant treatment and display day. $L^{*}$ and $a^{*}$ values, milligrams of malonaldehyde per kilogram, pull day, and display color and surface discoloration served as the dependent variables. There were 72 patties18 per treatment-in MP. Number of patties differ in MP versus MAP and PVC to ensure consistent number $(n=6)$ for each day (day 3, 6, 9, 12) for lipid oxidation measurements. For all models, least-squares means and standard error of the menas were generated.
When a significant F-test was identified $(P<0.05)$, least-squares means were separated using a pairwise $t$ test (PDIFF option).

\section{Results and Discussion}

\section{Instrumental color measurements}

A packaging $\times$ retail display $(P<0.0001)$ interaction for $L^{*}$ values was observed between patties packaged in PVC and MAP (Figure 1). Patties packaged with MAP were not different $(P>0.05)$ for $L^{*}$ values from day 0 to day 6 . As expected, $L^{*}$ values of patties packaged in PVC packages decreased $(P<0.05)$ from day 0 to day 6 . These findings are consistent with Suman et al. (2010), who reported that ground beef patties decreased in $L^{*}$ values over a 6-d display period. On day 0, patties packaged in PVC were lighter $(P<0.05)$ than patties packaged in MAP, but by day 3 the opposite was found $(P<0.05)$, and the trend continued throughout the display period. Rogers et al. (2014) found similar $L^{*}$ values between ground beef patties packaged in PVC and MAP compared with the $L^{*}$ values from this study. Additionally, there was a treatment effect $(P=0.008)$ for $L^{*}$ values, which is shown in Figure 2. Patties from the rosemary + green tea treatment were darker $(P<0.05)$ than control patties, as indicated by lower $L^{*}$ values; however, they

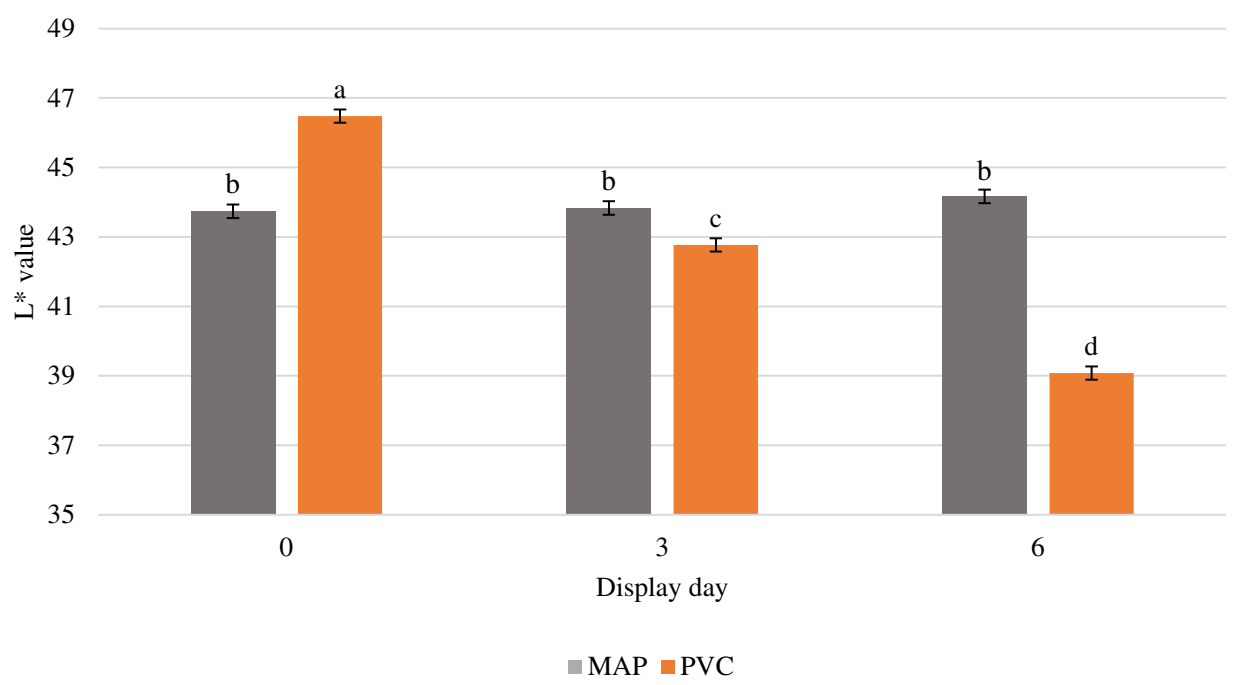
display.

Figure 1. Least-squares means for $L^{*}$ values with a packaging ${ }^{1} \times$ display day interaction of ground beef patties displayed for $7 \mathrm{~d}$ in simulated retail ${ }^{1} \mathbf{P V}$ dioxide).

${ }^{2}$ Forty-eight samples were analyzed per packaging treatment.

${ }^{\text {a-d }}$ Least-squares means values without a common subscript differ $(P<0.05)$.

Standard error bars are indicated for overall packaging $x$ day interaction $(S E=0.19)$. 


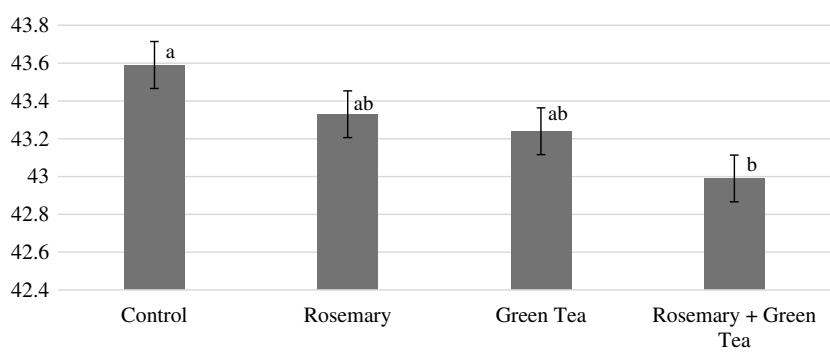

Figure 2. Least-squares means for $L^{*}$ values on ground beef patties displayed for $7 \mathrm{~d}$ in simulated retail display with a treatment ${ }^{1}$ effect.

${ }^{1}$ Forty-eight total samples were analyzed.

${ }^{2}$ Treatments include control, rosemary $2,500 \mathrm{ppm}$, green tea 300 ppm, and rosemary 2,500 + green tea $300 \mathrm{ppm}$.

${ }^{a, b}$ Least-squares means values without a common subscript differ $(\boldsymbol{P}<\mathbf{0 . 0 5})$.

Standard error bars are indicated for antioxidant treatment affect $(\mathrm{SE}=\mathbf{0 . 1 2})$.

were not darker than rosemary $(P>0.05)$ or green tea $(P>0.05)$ patties. Bouarab-Chibane et al. (2017) noted that green tea patties and control patties did not have statistically different $L^{*}$ values after $8 \mathrm{~d}$ of storage, similar to findings in this study, as green tea patties and control patties were not different $(P>0.05)$ regardless of packaging type or day of retail display.

There was a packaging $x$ treatment $\times$ day interaction $(P<0.0001)$ for $a^{*}$ values of patties packaged in PVC and MAP packaging (Table 1). On day 0, patties packaged in PVC had higher $(P<0.05) a^{*}$ values than patties in MAP, regardless of antioxidant treatment. However, this may be due to the conversion of oxymyoglobin to carboxymyoglobin through deoxymyoglobin (American Meat Science Association, 2012). By day 3, all patties packaged with MAP had higher $(P<0.05) a^{*}$ values than patties packaged in
PVC, and this difference remained higher throughout the display period, which aligns with results reported by Jeong and Claus (2011) for $a^{*}$ values of patties in MAP. Another study found that control patties packaged with PVC decreased in $a^{*}$ values after $5 \mathrm{~d}$ of retail display but that patties packaged in MAP with CO did not differ (Rogers et al., 2014). In the present study, all patties packaged with MAP were redder $(P<0.05)$ by day 3 of the display period. Of the patties packaged with MAP on day 6 , those with green tea were redder $(P<0.05)$ than patties with rosemary + green tea treatment, but patties with green tea were not different $(P>$ $0.05)$ than other treatments. By day 6 , rosemary patties packaged in PVC had higher $(P<0.05) a^{*}$ values than any other patties in PVC; however, $a^{*}$ values were not as high as those of patties packaged with MAP. These findings were consistent with Luño et al. (1998), who reported that ground beef patties packaged with MAP had acceptable $a^{*}$ values after $28 \mathrm{~d}$ of storage. Lee et al. (2005) also noted that, after $6 \mathrm{~d}$ of display, patties packaged in PVC and the rosemary antioxidant treatment had significantly higher $a^{*}$ values than control patties. Patties kept in high $\mathrm{O}_{2}$ MAP with added green tea leaves were shown to have significantly lower $a^{*}$ values than control (Bouarab-Chibane et al., 2017). Although this does not match the findings found in this study, this may be due to an oxygen content that was more similar to PVC, which did have lower $a^{*}$ values when green tea was added compared with control.

Patties packaged with MP had a treatment $\times$ day interaction for $L^{*}$ values as shown in Figure 3. On day 0 and day 6 , patties from each antioxidant treatment were not different $(P>0.05)$; however, on day 6 ,

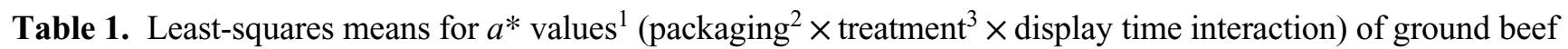
patties ${ }^{4}$ displayed for $7 \mathrm{~d}$

\begin{tabular}{|c|c|c|c|c|c|}
\hline Parameter & Packaging $^{2}$ & Treatment $^{3}$ & $\overline{\text { Display day } 0}$ & Display day 3 & $\overline{\text { Display day } 6}$ \\
\hline \multirow[t]{8}{*}{$a^{*}$ values $\mathrm{SE}=0.44$} & $\mathrm{PVC}$ & Control & $32.02^{\text {au }}$ & $21.14^{\mathrm{bw}}$ & $19.42^{\mathrm{bx}}$ \\
\hline & & Rosemary & $31.58^{\mathrm{au}}$ & $17.66^{\mathrm{cx}}$ & $22.49^{\mathrm{bw}}$ \\
\hline & & Green tea & $32.50^{\text {au }}$ & $20.71^{\text {bv }}$ & $18.95^{\mathrm{cx}}$ \\
\hline & & Rosemary + green tea & $31.48^{\text {au }}$ & $19.37^{\text {bw }}$ & $19.02^{\mathrm{bx}}$ \\
\hline & MAP & Control & $22.01^{\mathrm{cw}}$ & $26.80^{\text {bu }}$ & $28.44^{\text {auv }}$ \\
\hline & & Rosemary & $22.54^{\mathrm{bvw}}$ & $26.77^{\text {au }}$ & $28.50^{\text {auv }}$ \\
\hline & & Green tea & $22.68^{\mathrm{cvw}}$ & $27.48^{\text {bu }}$ & $29.52^{\text {au }}$ \\
\hline & & Rosemary + green tea & $23.29^{\mathrm{bv}}$ & $26.78^{\text {au }}$ & $27.64^{\mathrm{av}}$ \\
\hline
\end{tabular}

\footnotetext{
${ }^{1} \mathrm{~A}$ greater $a^{*}$ value represents redder meat.

${ }^{3}$ Treatments include control, rosemary $2,500 \mathrm{ppm}$, green tea $300 \mathrm{ppm}$, and rosemary 2,500+ green tea 300 ppm.

${ }^{4}$ Forty-eight samples were analyzed per packaging treatment.

${ }^{\mathrm{a}-\mathrm{c}}$ Within a row, least-squares means without a common superscript differ $(P<0.05)$.

${ }^{\mathrm{u}-\mathrm{x}}$ Within a column, least-squares means without a common superscript differ $(P<0.05)$.
}

${ }^{2} \mathrm{PVC}=$ polyvinyl chloride overwrap; MAP $=$ modified atmosphere packaging $(0.4 \%$ carbon monoxide, $69.6 \%$ nitrogen, and $30 \%$ carbon dioxide) 


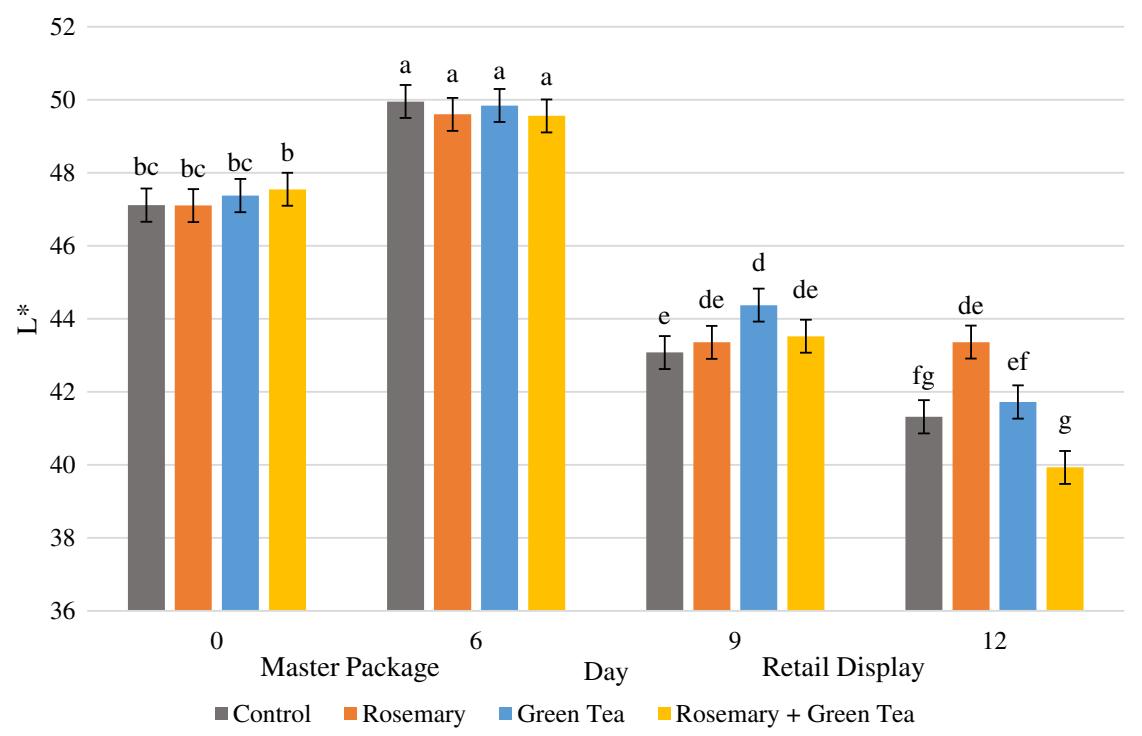

Figure 3. Least-squares means for $L^{*}$ values with a treatment ${ }^{1} \times$ display day interaction of ground beef patties in dark storage master packages ${ }^{2}$ for $7 \mathrm{~d}$ then in simulated retail display for $7 \mathrm{~d}$.

${ }^{1}$ Treatments include control, rosemary $2,500 \mathrm{ppm}$, green tea $300 \mathrm{ppm}$, and rosemary $2,500+$ green tea $300 \mathrm{ppm}$.

${ }^{2}$ Ninety-six total samples were evaluated.

${ }^{3}$ Master packages $(0.4 \%$ carbon monoxide, $69.6 \%$ nitrogen, and $30 \%$ carbon dioxide).

${ }^{\mathrm{a}-\mathrm{g}}$ Least-squares means values without a common subscript differ $(P<0.05)$.

Standard error bars are indicated for overall packaging $x$ day interaction $(\mathrm{SE}=0.45)$.

when removed from MP and placed in retail display, they all had higher $(P<0.05) L^{*}$ values than on other days. Jayasingh et al. (2001) and Lavieri and Williams (2014) reported similar results; patties packaged with MP after a week increased in $L^{*}$ values from day 0 . By day 9 , all patties had lower $(P<0.05) L^{*}$ values from day 6 , after opening MP and being placed in retail display. $L^{*}$ values for green tea patties were higher $(P<0.05)$ than control patties, but neither were different $(P>0.05)$ from the rosemary or rosemary + green tea patties on day 9 . From day 9 to 12 , rosemary was the only antioxidant treatment that did not decrease $(P>$ $0.05)$ in $L^{*}$ values.

Patties packaged with MP had a treatment $\times$ day interaction for $a^{*}$ values as shown in Figure 4. On day 0 or 6 regardless of treatment, no patties had different $(P>0.05) a^{*}$ values. This contradicts the findings from De Santos et al. (2007) and Lavieri and Williams (2014), both of whom showed that the longer ground beef and pork were in MP, the higher the $a^{*}$ value. Watts et al. (1978) concluded that when CO is absorbed by ground beef in packaging and then exposed to atmospheric gases, it has a half-life of $3 \mathrm{~d}$, which coincides with the results of this study, as patties on day 9 had lower $(P<0.05) a^{*}$ values than on day 6 . On day 9 , green tea and rosemary + green tea patties were not different $(P>0.05)$; however, both had higher $(P<0.05)$ $a^{*}$ values than control, which was also redder $(P<0.05)$ than rosemary patties. All patties on day 12 had similar $(P>0.05) a^{*}$ values. Jeong and Claus (2011) reported that, when ground beef patties were immediately removed from MP after 6-d duration, patties had much lower $a^{*}$ values than those found in this study, regardless of antioxidant additive; however, they did not include an oxygen scavenger in the MP.

\section{Visual color analysis}

There was a packaging $\times$ day $(P<0.0001)$ interaction for display color values for patties packaged with PVC and MAP (Figure 5). On day 0, patties packaged in PVC packaging were brighter $(P<0.05)$ than patties packaged with MAP. However, by day 2, patties packaged with MAP were not different $(P>0.05)$ in display color from patties packaged in PVC. From day 4 to day 6 , patties packaged with MAP did not change $(P>$ 0.05); conversely, patties packaged in PVC increased (darkened) $(P<0.05)$ in display color values. In a study conducted by Rogers et al. (2014), a trained color panel found that after $5 \mathrm{~d}$ of dark storage, ground beef patties in PVC were significantly $(P<0.05)$ darker than patties in MAP.

Surface discoloration had a packaging $\times$ treatment $\times$ day interaction $(P<0.05)$ for patties packaged with PVC and MAP (Table 2). On day 0, there was no discoloration on any patties regardless of the treatment 


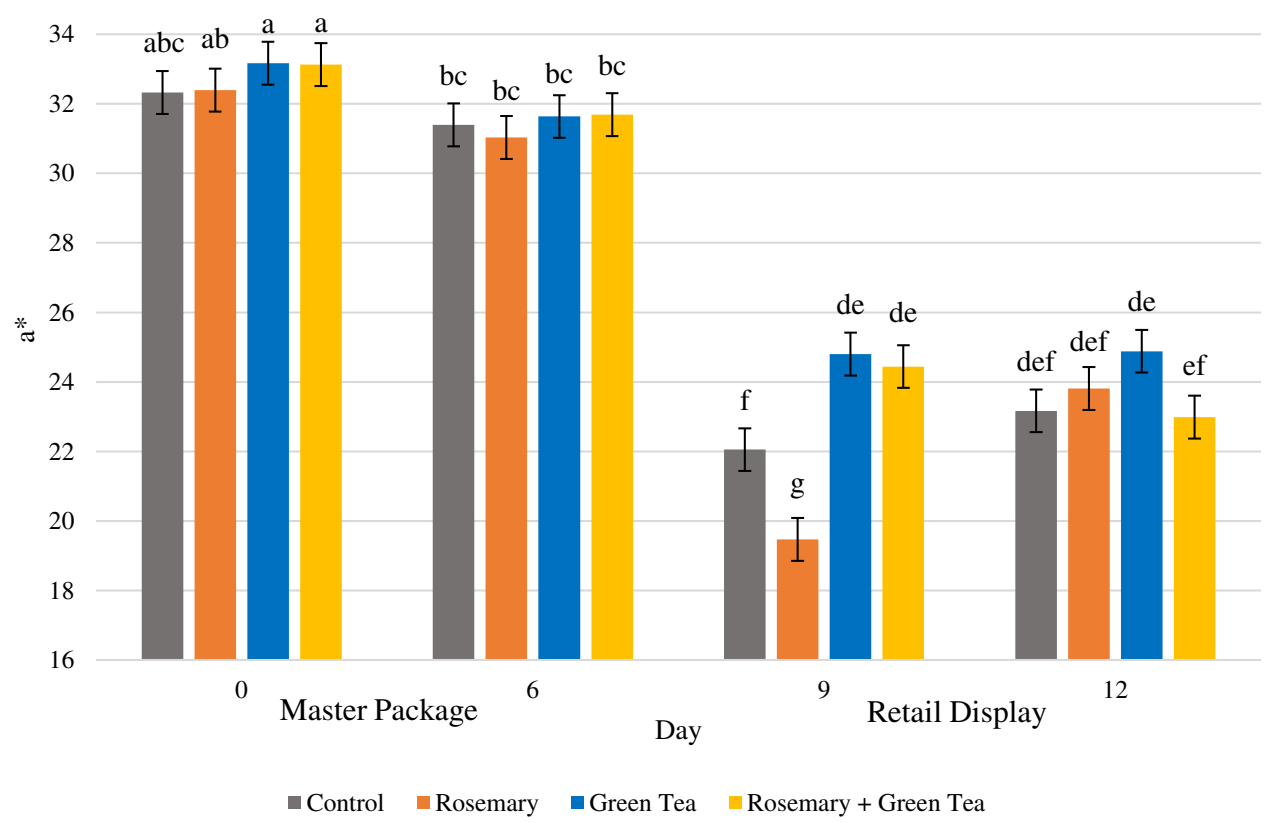

Figure 4. Least-squares means of treatment ${ }^{1} \times$ day interaction for $a^{*}$ values of ground beef patties in master packages ${ }^{2}$ in dark storage for $7 \mathrm{~d}$ then in simulated retail display for $7 \mathrm{~d}$.

${ }^{1}$ Treatments include control, rosemary $2,500 \mathrm{ppm}$, green tea $300 \mathrm{ppm}$, and rosemary $2,500+$ green tea $300 \mathrm{ppm}$.

${ }^{2}$ Ninety-six total samples were evaluated.

${ }^{3}$ Master packages $(0.4 \%$ carbon monoxide, $69.6 \%$ nitrogen, and $30 \%$ carbon dioxide).

${ }^{\mathrm{a}-\mathrm{g}}$ Least-squares means without a common superscript differ $(P<0.05)$.

Standard error bars are indicated for overall packaging $x$ day interaction $(\mathrm{SE}=0.62)$.

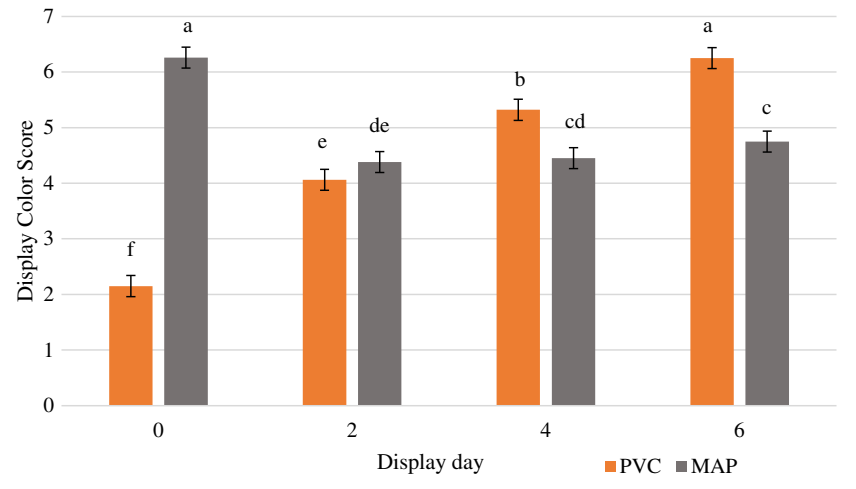

Figure 5. Least-squares means for display color values ${ }^{1}$ (packaging $^{2} \times$ day interaction) of ground beef displayed for $7 \mathrm{~d}$.

Display color was evaluated on an 8-point scale $(1=$ very light red, $2=$ moderately light red, $3=$ light red, $4=$ slightly bright red, $5=$ bright red, $6=$ slightly dark red, $7=$ moderately dark red, $8=$ dark red).

${ }^{1}$ A lower display color score indicates a brighter color $(1=$ very light red, $7=$ dark red).

${ }^{2} \mathrm{PVC}=$ polyvinyl chloride overwrap; $\mathrm{MAP}=$ modified atmosphere packaging $(0.4 \%$ carbon monoxide, $69.6 \%$ nitrogen, and $30 \%$ carbon dioxide).

${ }^{3}$ Forty-eight samples were evaluated per packaging treatment.

${ }^{a-f}$ Least-squares means values without a common subscript differ $(P<0.05)$.

Standard error bars are indicated for overall packaging $x$ day interaction $(\mathrm{SE}=0.19)$. or packaging type, which continued into day 3 for all patties packaged with MAP. On day 3, patties with rosemary treatment packaged in PVC had greater $(P<0.05)$ surface discoloration score than any other treatment. By day 6, patties packaged in PVC had discolored $(P<$ $0.05)$ more than patties packaged with MAP, regardless of antioxidant treatment. Arvanitoyannis and Stratakos (2012) discussed how many studies have observed and found that CO in MAP improves color stability because of carboxymyoglobin formation. Control and green tea patties packaged in PVC on day 6 had the most discoloration $(P<0.05)$. Sánchez-Escalante et al. (2003) reported that rosemary inhibited metmyoglobin formation in ground beef patties compared with control patties in MAP for $20 \mathrm{~d}$.

For both display color and surface discoloration, there was a treatment $x$ day interaction that occurred for patties in MP; results are shown in Table 3. From day 6 to 12 , values increased $(P<0.05)$, regardless of the antioxidant treatment for both display color and surface discoloration. Display color and surface discoloration were similar among all treatment types on day 6. Hunt et al. (2004) reported that, after $21 \mathrm{~d}$ in MP and $1 \mathrm{~d}$ in retail display, the display color of ground beef patties was scored by panelists similarly to patties in traditional PVC on day 1 that were not 
Table 2. Least-squares means for surface discoloration values ${ }^{1}$ (packaging ${ }^{2} \times$ treatment $^{3} \times$ display $_{\text {time }}$ interaction) of ground beef patties ${ }^{4}$ displayed for $7 \mathrm{~d}$

\begin{tabular}{|c|c|c|c|c|c|}
\hline Parameter & Packaging $^{2}$ & Treatment $^{3}$ & Display day 0 & Display day 3 & Display day 6 \\
\hline \multirow[t]{8}{*}{ Surface discoloration $\mathrm{SE}=\mathbf{0 . 1 9}$} & $\mathrm{PVC}$ & Control & $1.00^{\mathrm{c}}$ & $2.37^{\mathrm{bv}}$ & $5.14^{\text {au }}$ \\
\hline & & Rosemary & $1.00^{\mathrm{b}}$ & $4.21^{\mathrm{au}}$ & $4.40^{\mathrm{av}}$ \\
\hline & & Green tea & $1.00^{\mathrm{c}}$ & $2.56^{\mathrm{bv}}$ & $5.56^{\mathrm{au}}$ \\
\hline & & Rosemary + green tea & $1.00^{\mathrm{c}}$ & $2.73^{\mathrm{bv}}$ & $4.53^{\mathrm{av}}$ \\
\hline & MAP & Control & 1.00 & $1.00^{\mathrm{w}}$ & $1.19^{\mathrm{w}}$ \\
\hline & & Rosemary & 1.00 & $1.19^{\mathrm{w}}$ & $1.39^{\mathrm{w}}$ \\
\hline & & Green tea & 1.00 & $1.00^{\mathrm{w}}$ & $1.14^{\mathrm{w}}$ \\
\hline & & Rosemary + green tea & $1.00^{\mathrm{b}}$ & $1.00^{\mathrm{bw}}$ & $1.57^{\mathrm{aw}}$ \\
\hline
\end{tabular}

Surface discoloration was evaluated on a 7-point scale $(1=$ no discoloration $0 \%$ [metmyoglobin]; $2=$ minimal discoloration $1 \%-10 \% ; 3=$ slight discoloration $11 \%-20 \% ; 4=$ small discoloration $21 \%-40 \%$; $5=$ modest discoloration $41 \%-60 \%$; $6=$ moderate discoloration $61 \%-80 \%$; $7=$ extensive discoloration $81 \%-100 \%)$.

1A lower surface discoloration indicates less discoloration and metmyoglobin formation $(1=$ no discoloration [ $0 \%$ metmyoglobin]; $7=$ extensive discoloration $[81 \%-100 \%])$.

$2 \mathrm{PVC}=$ polyvinyl chloride overwrap; $\mathrm{MAP}=$ modified atmosphere packaging $(0.4 \%$ carbon monoxide, $69.6 \%$ nitrogen, and $30 \%$ carbon dioxide $)$.

3 Treatments include: control, rosemary $2500 \mathrm{ppm}$, green tea $300 \mathrm{ppm}$, and rosemary $2500+$ green tea $300 \mathrm{ppm}$.

4 Forty-eight samples were analyzed per packaging treatment.

a-cWithin a row, least-squares means without a common superscript differ $(P<0.05)$.

$\mathrm{u}-\mathrm{wWithin}$ a column, least-squares means without a common superscript differ $(P<0.05)$.

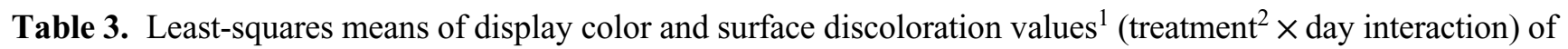
ground beef patties ${ }^{3}$ in master packages ${ }^{4}$ in simulated retail display for $7 \mathrm{~d}$ after dark storage

\begin{tabular}{|c|c|c|c|c|}
\hline Parameter & Treatment $^{3}$ & Display day 6 & Display day 9 & Display day 12 \\
\hline \multirow[t]{4}{*}{ Display color $\mathrm{SE}=0.29$} & Control & $2.21^{\mathrm{c}}$ & $4.37^{\text {bu }}$ & $6.39^{\text {auv }}$ \\
\hline & Rosemary & $2.01^{\mathrm{c}}$ & $5.12^{\text {bu }}$ & $6.35^{\text {auv }}$ \\
\hline & Green tea & $1.91^{\mathrm{c}}$ & $3.86^{\mathrm{bv}}$ & $6.09^{\mathrm{av}}$ \\
\hline & Rosemary + green tea & $1.99^{\mathrm{c}}$ & $3.88^{\text {bv }}$ & $6.71^{\text {au }}$ \\
\hline \multirow[t]{4}{*}{ Surface discoloration $\mathrm{SE}=\mathbf{0 . 2 8}$} & Control & $1.01^{\mathrm{c}}$ & $3.03^{\text {bu }}$ & $4.92^{\text {auv }}$ \\
\hline & Rosemary & $1.01^{\mathrm{c}}$ & $3.17^{\mathrm{bu}}$ & $4.92^{\mathrm{auv}}$ \\
\hline & Green tea & $1.00^{\mathrm{c}}$ & $2.02^{\text {buv }}$ & $4.78^{\mathrm{av}}$ \\
\hline & Rosemary + green tea & $1.06^{\mathrm{c}}$ & $2.17^{\text {buv }}$ & $5.28^{\mathrm{au}}$ \\
\hline
\end{tabular}

Surface discoloration was evaluated on a 7-point scale $(1=$ no discoloration $0 \%$ [metmyoglobin]; $2=$ minimal discoloration $1 \%-10 \% ; 3=$ slight discoloration $11 \%-20 \% ; 4=$ small discoloration $21 \%-40 \% ; 5=$ modest discoloration $41 \%-60 \%$; $6=$ moderate discoloration $61 \%-80 \%$; $7=$ extensive discoloration $81 \%-100 \%)$.

${ }^{1}$ A lower display color score indicates a brighter color $(1=$ very light red, $7=$ dark red $)$; a lower surface discoloration indicates less discoloration and metmyoglobin formation $(1=$ no discoloration $[0 \%$ metmyoglobin], 7 = extensive discoloration $[81 \%-100 \%]$ ).

${ }^{2}$ Treatments included control, rosemary $2,500 \mathrm{ppm}$, green tea $300 \mathrm{ppm}$, and rosemary $2,500+$ green tea $300 \mathrm{ppm}$.

${ }^{3}$ Forty-eight samples were analyzed.

${ }^{4}$ Master packages ( $0.4 \%$ carbon monoxide, $69.6 \%$ nitrogen, and 30\% carbon dioxide).

${ }^{\mathrm{a}-\mathrm{c}}$ Within a row, least-squares means without a common superscript differ $(P<0.05)$.

${ }^{\mathrm{u}, \mathrm{v}}$ Within a column of the same parameter, least-squares means without a common superscript differ $(P<0.05)$.

stored in MP, which is similar to the findings in this study. On day 9, patties with green tea and rosemary + green tea had lower $(P<0.05)$ display color values than control and rosemary patties. Greene et al. (1971) established that $40 \%$ metmyoglobin causes rejection of meat products by consumers; therefore, day-9 values of surface discoloration would indicate that they may have been rejected. Luño et al. (2000) found that patties in MP showed no discoloration after $10 \mathrm{~d}$ inside MP and did not show any signs of discoloration until day 15 in MP.

\section{Lipid oxidation analysis}

A significant packaging $\times$ treatment interaction $(P<0.0001)$ was determined for lipid oxidation 
analysis of patties in PVC and MAP (Table 4). In PVC, patties with an antioxidant addition had lower $(P<$ $0.05)$ lipid oxidation values compared with control patties. Patties with green tea and rosemary + green tea packaged in PVC had higher $(P<0.05)$ values than patties with just rosemary. These results align with Schilling et al. (2018), who reported that the combination of rosemary + green tea showed greater lipid oxidation inhibition than rosemary added alone. Yet, in this study, green tea inhibited lipid oxidation as well as rosemary + green tea, whereas Schilling et al. (2018) noted no difference between green tea and rosemary + green tea. Additionally, there was a

Table 4. Least-squares means of packaging $^{1} \times$ treatment $^{2}$ interaction for lipid oxidation ${ }^{3}$ values of ground beef patties ${ }^{4}$

\begin{tabular}{lllc}
\hline \hline Parameter & & \multicolumn{2}{c}{ Packaging } \\
\hline Lipid oxidation SE $=\mathbf{0 . 0 1}$ & Treatment & MAP & PVC \\
& Control & $0.36^{\mathrm{c}}$ & $0.59^{\mathrm{a}}$ \\
& Rosemary & $0.32^{\text {cde }}$ & $0.46^{\mathrm{b}}$ \\
& Green tea & $0.31^{\text {de }}$ & $0.35^{\text {cd }}$ \\
& Rosemary + green tea & $0.30^{\mathrm{e}}$ & $0.35^{\text {cd }}$ \\
\hline
\end{tabular}

${ }^{1} \mathrm{PVC}=$ polyvinyl chloride overwrap; $\mathrm{MAP}=$ modified atmosphere packaging $(0.4 \%$ carbon monoxide, $69.6 \%$ nitrogen, and $30 \%$ carbon dioxide).

${ }^{2}$ Treatments include control, rosemary $2,500 \mathrm{ppm}$, green tea $300 \mathrm{ppm}$, and rosemary $2,500+$ green tea $300 \mathrm{ppm}$.

${ }^{3}$ Values are shown as mg malonaldehyde/kg meat.

${ }^{4}$ Forty-eight samples were analyzed per packaging treatment.

${ }^{\mathrm{a}-\mathrm{e}}$ Within rows and columns, least-squares means without a common super script differ $(P<0.05)$. packaging $\times$ day interaction for lipid oxidation analysis of patties packaged with PVC and MAP. Patties packaged with MAP did not increase $(P>0.05)$ in lipid oxidation values from day 3 to day 6 , nor were they different $(P>0.05)$ from values measured on day 0 . On both day 3 and 6 of display, patties packaged with MAP had lower $(P<0.05)$ lipid oxidation values than those packaged in PVC. Lipid oxidation of patties packaged in PVC increased $(P<0.05)$ from day- 0 composite sample values on both day 3 and day 6 .

Patties packaged in MP had a treatment $\times$ day interaction $(P<0.05)$ for lipid oxidation values (Figure 6). After removal from MP on day 6, values for control patties were higher $(P<0.05)$ than values from day 0 ; however, patties with any antioxidant treatment were not different $(P>0.05)$. In contrast, Lavieri and Williams (2014) reported that, after $7 \mathrm{~d}$ in MP, ground beef patties with no added ingredients did not significantly increase in lipid oxidation values. All patties, no matter the antioxidant treatment, had higher $(P<0.05)$ lipid oxidation values on day 9 than day 6 . By day 12 , control and rosemary patties were not different $(P>$ $0.05)$ from control and rosemary patties evaluated on day 9.

\section{Trained sensory analysis}

Values for the trained sensory panel can be found in Table 5. Panelists detected no differences $(P>0.05)$ between all 4 antioxidant treatments for fatty flavor or rancid flavor. However, panelists did detect a difference $(P<0.05)$ in the green-hay flavor; patties with rosemary were reported to have a more detectable

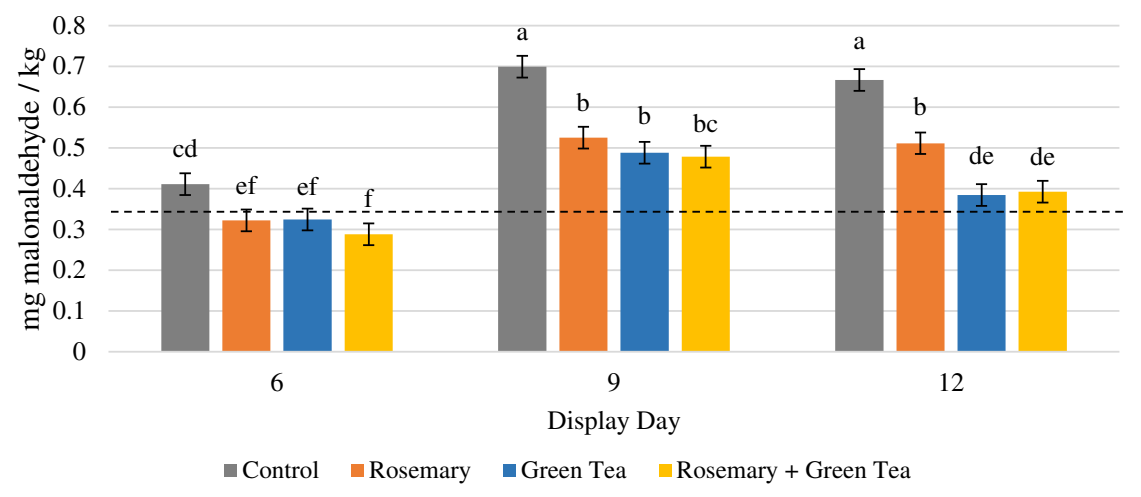

Figure 6. Least-squares means of treatment ${ }^{1} \times$ day interaction for lipid oxidation ${ }^{2}$ values of ground beef patties in dark storage master packages ${ }^{3}$ for $7 \mathrm{~d}$ then in simulated retail display for $7 \mathrm{~d}$.

${ }^{1}$ Treatments include control, rosemary $2,500 \mathrm{ppm}$, green tea $300 \mathrm{ppm}$, and rosemary $2,500+$ green tea $300 \mathrm{ppm}$.

${ }^{2}$ Values are shown as mg malonaldehyde/kg meat.

${ }^{3}$ Ninety-eight total samples were evaluated.

${ }^{4}$ Master packages $(0.4 \%$ carbon monoxide, $69.6 \%$ nitrogen, and $30 \%$ carbon dioxide).

${ }^{a-f}$ Least-squares means values without a common subscript differ $(P<0.05)$.

Dashed line indicates least-squares means value of composite sample tested on day 0 in no packaging (LS means $=0.336)$.

Standard error bars are indicated for overall packaging $x$ day interaction $(\mathrm{SE}=0.03)$. 
Table 5. Least-squares means of sensory analysis traits of ground beef patties with four treatments ${ }^{1}$

\begin{tabular}{lllll}
\hline \hline Parameter & Attribute & $\boldsymbol{P}$ value & Treatment & \\
\hline $\begin{array}{l}\text { Sensory } \\
\text { evaluation }\end{array}$ & Green hay & $<0.0001$ & Control & $1.02^{\mathrm{c}}$ \\
& (SE $=0.09)$ & & & \\
& & & Rosemary & $1.86^{\mathrm{a}}$ \\
& & & Green tea & $1.00^{\mathrm{c}}$ \\
& & & Rosemary + & $1.50^{\mathrm{b}}$ \\
& Fatty & 0.64 & & \\
& Rancid & 0.32 & & \\
\hline
\end{tabular}

\footnotetext{
${ }^{1}$ Treatments include: control, rosemary $2,500 \mathrm{ppm}$, green tea $300 \mathrm{ppm}$, and rosemary $2,500+$ green tea $300 \mathrm{ppm}$.

${ }^{\mathrm{a}-\mathrm{c}}$ Least-squares means values without a common subscript differ $(P<0.05)$

Three patties were prepared, coded with a random 3-digit number, and randomly served to panelists each session, with 3 sessions total.
}

green-hay flavor than all other treatments followed by rosemary + green tea having more detectable green hay flavor than green tea and control patties. Panelists detected no differences $(P<0.05)$ for greenhay flavor between control and green tea patties. Jayawardana et al. (2019) reported that consumers could not taste a difference in overall flavor between sausages with green tea versus without, which is similar to the findings from this study. Bouarab-Chibane et al. (2017) noted different results when using a discrimination test between green tea and control patties, as a majority of the consumers rated the patties with a spinach-like taste; however, this is probably due to using whole green tea leaves, rather than an extract.

\section{Conclusions}

Ground beef is the most consumed beef product in the United States; however, the shelf life is lower than other beef products because of the grinding process and increased surface area exposed to pro-oxidants. Improving shelf life of ground beef products can reduce food waste and loss by allowing retailers to keep product on the shelf longer before discounting or discarding. Utilizing MAP and MP with $\mathrm{CO}$ and $\mathrm{CO}_{2}$ gases can improve the shelf life of ground beef and other meat products through the formation of carboxymyoglobin prior to being exposed to atmospheric $\mathrm{O}_{2}$. The addition of green tea improved subjective color measurements and $L^{*}$ values when meat was packaged with MP; however, no other instrumental color measurements were affected. Patties with green tea and rosemary + green tea antioxidant treatments packaged with MP and $3 \mathrm{~d}$ of retail display showed increased $a^{*}$ and chroma values and lower display color values compared with control or rosemary patties, as well as lower lipid oxidation values than control patties. Additionally, the inability of sensory panelists to differentiate between control patties and patties with green tea indicates that this may be an avenue for further research because it may provide greater opportunities for a label-friendly antioxidant without impacting sensory characteristics. Overall, research findings were inconclusive regarding these antioxidant usage levels in combination with these packaging types and/or for these display periods; however, a greater understanding of plant-derived antioxidants is needed. Greater usage levels of green tea added singly or in combination with other plant antioxidants could positively impact color shelf life but negatively impact sensory attributes. The use of plantderived antioxidants, addition levels, and sensory implications in meat products should be explored further when used in combination with MAP or MP, as these antioxidants may improve color stability and shelf life of meat products.

\section{Literature Cited}

American Meat Science Association. 2012. AMSA meat color measurement guidelines. Am. Meat Sci. Assoc., Champaign, IL.

American Meat Science Association. 2016. Research guidelines for cookery, sensory evaluation, and instrumental tenderness measurements of meat. Am. Meat Sci. Assoc., Champaign, IL.

Arvanitoyannis, I. S., and Stratakos, A. C. 2012. Application of modified atmosphere packaging and active/smart technologies to red meat and poultry: A Review. Food Bioprocess Tech. 5:1423-1446. https://doi.org/10.1007/ s11947-012-0803-z.

Balentine, C. W., P. G. Crandall, C. A. O’Bryan, D. Q. Duong, and F. W. Pohlman. 2006. The pre- and post-grinding application of rosemary and its effects on lipid oxidation and color during storage of ground beef. Meat Sci. 73:413-421. https://doi.org/ 10.1016/j.meatsci.2005.12.003.

Bañón, S., P. Díaz, M. Rodríguez, M. D. Garrido, and A. Price. 2007. Ascorbate, green teaand grape seed extracts increase the shelf life of low sulphite beef patties. Meat Sci. 77:626633. https://doi.org/10.1016/j.meatsci.2007.05.015.

Bechtel, P. J., M. L. Greaser, A. M. Pearson, R. Hamm, G. R. Schmidt, A. A. Kraft, H. R. Cross, P. R. Durland, S. C. Seideman, C. E. Bodwell, B. A. Anderson, P. B. Addis, and W. D. Brown. 1986. Muscle as Food. Academic Press, Inc, San Diego.

Bouarab-Chibane, L., B. Ouled-Bouhedda, L. Leonard, L. Gemelas, J. Bouajila, H. Ferhout, A. Cottaz, C. Joly, P. Degraeve, and N. Oulahal. 2017. Preservation of fresh ground beef patties using plant extracts combined with a modified atmosphere packaging. Eur. Food Res. Technol. 243:19972009. https://doi.org/10.1007/s00217-017-2905-3. 
De Santos, F., M. Rojas, G. Lockhorn, and M. Brewer. 2007. Effect of carbon monoxide in modified atmosphere packaging, storage time and endpoint cooking temperature on the internal color of enhanced pork. Meat Sci. 77:520-528. https://doi. org/10.1016/j.meatsci.2007.04.031.

Denzer, M. L., A. M. Cassens, K. M. Wills, M. M. Pfeiffer, G. G. Mafi, D. L. VanOverbeke, and R. Ramanathan. 2020. Effects of enhancement and modified atmosphere packaging on flavor and tenderness of dark-cutting beef." Meat Muscle Biol. 4(1). https://doi.org/10.22175/mmb.11157.

Falowo, A. B., P. O. Fayemi, and V. Muchenje. 2014. Natural antioxidants against lipid-protein oxidative deterioration in meat and meat products: A review. Food Res Int. 64:171-181. https://doi.org/10.1016/j.foodres.2014.06.022.

Font-i-Furnols, M., and L. Guerrero. 2014. Consumer preference, behavior, and perception about meat and meat products: An overview. Meat Sci. 98:361-371. https://doi.org/10.1016/j. meatsci.2014.06.025.

Greene, B. E., I. M. Hsin, and M. Y. W. Zipser. 1971. Retardation of oxidative color changes in raw ground beef. J. Food Sci. 36:940 942. https://doi.org/10.1111/j.13652621.1971.tb15564.x.

Hunt, M. C., R. A. Mancini, K. A. Hachmeister, D. H. Kropf, M. Merriman, G. Delduca, and G. Milliken. 2004. Carbon monoxide in modified atmosphere packaging affects color, shelf life, and microorganisms of beef steaks and ground beef. J. Food Sci. 69:FCT45-FCT52. https://doi.org/10.1111/j. 1365-2621.2004.tb17854.x.

Jayasingh, P., D. P. Cornforth, C. E. Carpenter, and D. Whittier. 2001. Evaluation of carbon monoxide treatment in modified atmosphere packaging or vacuum packaging to increase color stability of fresh beef. Meat Sci. 59:317-324. https://doi.org/ 10.1016/S0309-1740(01)00086-9.

Jayawardana, B. C., V. B. Warnasooriya, G. H. Thotawattage, V. A. K. I. Dharmasena, and R. Liyanage. 2019. Black and green tea (Camellia sinensis L.) extracts as natural antioxidants in uncured pork sausages. J. Food Process Pres. 43:e13870. https://doi.org/10.1111/jfpp.13870.

Jeong, J. Y., and J. R. Claus. 2011. Color stability of ground beef packaged in a low carbonmonoxide atmosphere or vacuum. Meat Sci. 87:1-6. https://doi.org/10.1016/j.meatsci.2010.08.004.

Knobel, S. M., G. G. Mafi, C. Mireles De Witt, J. B. Morgan, C. J. Richards, and D. L. VanOverbeke. 2013. The impact of postharvest interventions on the color stability and, subsequently, the palatability of beef from cattle fed wet distillers grain. J. Anim. Sci. 91:1468-1479. https://doi.org/10.2527/jas.2012-5558.

Lavieri, N., and S. K. Williams. 2014. Effects of packaging systems and fat concentrations on microbiology, sensory and physical properties of ground beef stored at $4 \pm 1{ }^{\circ} \mathrm{C}$ for 25 days. Meat Sci. 97:534-541. https://doi.org/10.1016/j.meatsci.2014.02.014.

Lee, S., E. A. Decker, C. Faustman, and R. A. Mancini. 2005. The effects of antioxidant combinations on color and lipid oxidation in $\mathrm{n}-3$ oil fortified ground beef patties. Meat Sci. 70:683689. https://doi.org/10.1016/j.meatsci.2005.02.017.

Liu, F., Q. Xu, R. Dai, and Y. Ni. 2015. Effects of natural antioxidants on colour stability, lipid oxidation and metmyoglobin reducing activity in raw beef patties. Acta Sci. Pol. Technol. Aliment. 14:37-44. https://doi.org/10.17306/J. AFS.2015.1.4.
Luño, M., J. A. Beltrán, and P. Roncalés. 1998. Shelf-life extension and colour stabilisation of beef packaged in a low $\mathrm{O} 2$ atmosphere containing CO: Loin steaks and ground meat. Meat Sci. 48:75-84. https://doi.org/10.1016/S0309-1740(97)00078-8.

Luño, M., P. Roncalés, D. Djenane, and J. A. Beltrán. 2000. Beef shelf life in low $\mathrm{O} 2$ and high $\mathrm{CO} 2$ atmospheres containing different low CO concentrations. Meat Sci. 55:413-419. https:// doi.org/10.1016/S0309-1740(99)00170-9.

Maia Research Analysis Global. 2020. Meat wastage at store or losses due to discoloration of meat 2015-2020. Report purchased 20 July 2020. https://www.maiaresearch.com. (Accessed 2020).

McMillin, K. W. 2017. Advancements in meat packaging. Meat Sci. 132:153-162. https://doi.org/10.1016/j.meatsci.2017. 04.015 .

Oswell, N. J., H. Thippareddi, and R. B. Pegg. 2018. Practical use of natural antioxidants in meat products in the U.S.: A review. Meat Sci. 145:469-479. https://doi.org/10.1016/j.meatsci. 2018.07.020.

Ramanathan, R., N. M. Nair, M. C. Hunt, and S. P. Suman. 2019. Mitochondrial functionality and beef colour: A review of recent research. S. Afr. J. Anim. Sci. 49:9-19. https://doi. org/http://dx.doi.org/10.4314/sajas.v49i1.2.

Rogers, H. B., J. C. Brooks, J. N. Martin, A. Tittor, M. F. Miller, and M. M. Brashears. 2014. The impact of packaging system and temperature abuse on the shelf life characteristics of ground beef. Meat Sci. 97:1-10. https://doi.org/10.1016/j.meatsci. 2013.11.020.

Rulis, A. M. 2002. Agency response letter, re: GRAS notice no. GRN 000083. U.S. Food and Drug Administration, Center for Food Safety and Applied Nutrition website. https:// www.cfsanappsexternal.fda.gov/scripts/fdcc/index.cfm? set=GRASNotices\&id=83. (Accessed 13 January 2021).

Sánchez-Escalante, A., D. Djenane, G. Torrescano, J. A. Beltrán, and P. Roncales. 2003. Antioxidant action of borage, rosemary, oregano, and ascorbic acid in beef patties packaged in modified atmosphere. J. Food Sci. 68:339-344. https:// doi.org/10.1111/j.1365-2621.2003.tb14162.x.

Schilling, M. W., A. J. Pham, J. B. Williams, Y. L. Xiong, N. Dhowlaghar, A. C. Tolentino, and S. Kin. 2018. Changes in the physiochemical, microbial, and sensory characteristics of fresh pork sausage containing rosemary and green tea extracts during retail display. Meat Sci. 143:199-209. https://doi.org/10.1016/j.meatsci.2018.05.009.

Sørheim, O., H. Nissen, and T. Nesbakken. 1999. The storage life of beef and pork packaged inan atmosphere with low carbon monoxide and high carbon dioxide. Meat Sci. 52:157-164. https://doi.org/10.1016/S0309-1740(98)00163-6.

Suman, S. P., R. A. Mancini, P. Joseph, R. Ramanathan, M. K. R. Konda, G. Dady, and S. Yin.2010. Packaging-specific influence of chitosan on color stability and lipid oxidation in refrigerated ground beef. Meat Sci. 86:994-998. https://doi.org/10. 1016/j.meatsci.2010.08.006.

Watts, D. A., W. D. Brown, and S. K. Wolfe. 1978. Fate of [14C] carbon monoxide in cooked or stored ground beef samples. J. Agr. Food Chem. 26:210-214. https://doi.org/10.1021/ jf60215a069han. 